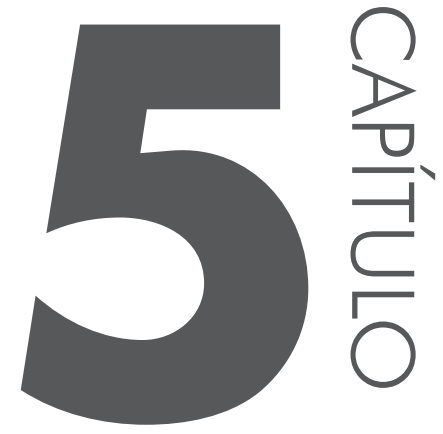

\title{
A RECENTE PRODUC̣ÃO TEÓRICA EM TORNO DOS DETERMINANTES SOCIAIS DA SAÚDE
}

Julliane Bispo Pereira ${ }^{1}$

Diego de Oliveira Souza ${ }^{2}$

\subsection{INTRODUC̣ÃO}

A partir do movimento da Reforma Sanitária Brasileira, em meados da década de 1980, observamos um considerável aumento da produção acadêmica sobre a saúde enquanto processo social. Além da conjuntura propícia para o aumento

1 Graduanda em Enfermagem pela Universidade Federal de Alagoas (UFAL) - Campus Arapiraca. Contato: jullianebispo@hotmail.com, (82) 9997-4702.

2 Enfermeiro, especialista em Enfermagem do Trabalho, mestre em Serviço Social, doutorando em Serviço Social e docente do curso de bacharelado em Enfermagem da Universidade Federal de Alagoas (UFAL) - Campus Arapiraca. Contato: enf_ufal_diego@hotmail.com, (82) 9631-8810. 
deste tipo de produção teórica, à época da Reforma, devemos destacar as importantes contribuições que alguns autores nacionais e estrangeiros vinham trazendo desde a década de 1970. Dentre eles, vale mencionar a brasileira Cecília Donnangelo e a mexicana Asa Cristina Laurell.

Donnangelo é considerada uma das pioneiras na construção de um pensamento social em saúde. Destacamos duas de suas obras: Medicina e Sociedade e Saúde e Sociedade, além de outros trabalhos publicados na metade dos anos 1970, nos quais propõe uma reflexão entre medicina/saúde/sociedade. Donnangelo investiga a organização do setor de produção de serviços de saúde, interpretando-o a partir da dinâmica das relações de classe na área urbano-social da sociedade brasileira. Além disto, trata a medicina como prática social em dada estrutura social e a constituição da medicina comunitária como uma prática assumida por determinadas sociedades, bem como pela produção de serviços de saúde em suas relações com a política do bem-estar social (NUNES, 2008).

Laurell, por sua vez, foi uma das teóricas responsáveis pelo impulso da discussão sobre a determinação social da saúde na década de 1980. Essa autora vê a relação saúde-doença como resultado de um processo histórico-social movido pela luta de classes. Ao defender a determinação social da doença, Laurell percebe que os extratos ou grupos sociais (em última estância: as classes sociais) constituem espaços, cada um com as suas particularidades próprias, para o desenvolvimento do processo saúde-doença, implicando substanciais diferenças de saúde entre estes grupos (LAURELL, 1982).

Atualmente a discussão está balizada no que se convencionou chamar de determinantes sociais da saúde (DSS). Contudo, ressaltamos que essa discussão vem ocorrendo por caminhos teórico-metodológicos diversos, afastando-se e, por vezes, contrapondo-se à matriz teórica original, que fundamentou as análises empreendidas nas décadas de 1970 e 1980 pelas autoras citadas acima.

Tal condição não representaria prejuízo caso se desenvolvesse enquanto debate de concepções divergentes. No entanto, temos notado que ela tem se configurado como uma colagem eclética de teorias e argumentos antagônicos e excludentes, conferindo caráter de incoerência e inconsistência à parte da produção sobre o tema, com distorção, inclusive, das formulações teóricas clássicas. Não obstante, as inconsistências se reproduzem nas propostas de intervenção sobre os supostos DSS. Diante disto, julgamos necessário realizar esta investigação, com o objetivo de analisar a recente produção teórica brasileira sobre os DSS.

Demonstraremos os fatores que correspondem ao fenômeno dos DSS, tais como a pobreza, as iniquidades de saúde, a globalização, entre outros. Durante o desenvolver dos capítulos, algumas conclusões vão sendo adiantadas para serem retomadas nas considerações finais. 


\subsection{METODOLOGIA}

Trata-se de uma revisão integrativa realizada no ano de 2012. Buscamos publicações na Biblioteca Virtual em Saúde (BVS) por meio do uso dos seguintes descritores em ciências da saúde (DeCS): condições sociais; problemas sociais; saúde pública.

Os critérios de inclusão das publicações foram: 1) terem sido publicadas no período entre janeiro de 2007 e dezembro de 2012; 2) possuírem como tema central a determinação social da saúde ou tratarem das iniquidades em saúde, da "questão social" e da relação sociedade $x$ saúde em geral. Foram excluídos os artigos que discutiam apenas um determinante isolado, bem como aqueles que retratavam apenas a doença (ponto de vista meramente biológico).

A análise do material se deu por meio da Técnica de Análise Imanente, que consiste em fichar detalhadamente o artigo para identificar as teses e categorias centrais do texto, entendendo a lógica interna e os princípios teóricos implícitos. No segundo momento deste tipo de análise, empreendemos um movimento para fora do texto, realizando uma crítica ontológica.

Esse tipo de crítica fundamenta-se na teoria social e no método Marxiano. Para Karl Marx é preciso estar sempre voltado para o processo histórico (real) do objeto estudado, ou seja, sua origem, natureza e função social. Neste sentido, a abordagem ontológica põe três referenciais metodológicos decisivos para a problemática do conhecimento: a categoria totalidade, a abordagem genética e o percurso de "ida e volta".

A priori, o pesquisador (sujeito da pesquisa) deve apreender a essência do objeto, o que implica ir além da aparência, isto é, esfera fenomênica, imediata e empírica. Em um segundo momento, a abordagem genética torna-se necessária para conhecer as formas do objeto e desvendar as suas origens, elucidando a historicidade do ser.

Após alcançar a processualidade histórica, pode-se retomar a dimensão fenomênica do objeto, revelando suas múltiplas determinações, o que constitui o chamado caminho de "ida e volta". O percurso de ida representa a decomposição analítico-abstrata do objeto. Partimos da realidade imediatamente dada, percebendo que, neste momento, não conseguimos apreender o que o objeto é, mas apenas o que ele não é. Nesse sentido, após analisar as partes e as mediações existentes, alcançando as ditas "determinações mais simples", ${ }^{3}$ faz-se um caminho inverso, até recompor o objeto (SOUZA, 2011).

3 Possui nexos categoriais tais como a interação entre singular-particular-universal e entre essência-fenômeno, a capacidade de abstração e de generalização, a relação entre objetividade e subjetividade e a causalidade, reunidos em um complexo de complexos (NETTO, 2011). 
Por conseguinte, o texto será descrito em quatro seções. A primeira seção evidencia a caracterização dos textos revisados. Feito isso, faremos uma breve exposição sobre a teoria dos DSS a fim de compreender sua definição e relações/ mediações. A terceira seção constitui o eixo Pobreza e Iniquidades de Saúde, no qual abordaremos estes temas de forma relacionada. A quarta seção faz um balanço crítico, resgatando os autores revisados.

\subsection{CARACTERIZAC̣ÃO DAS PUBLICAC̣õES REVISADAS}

A seleção realizada na BVS resultou em um total de 43 publicações. Ver Figura 5.1.
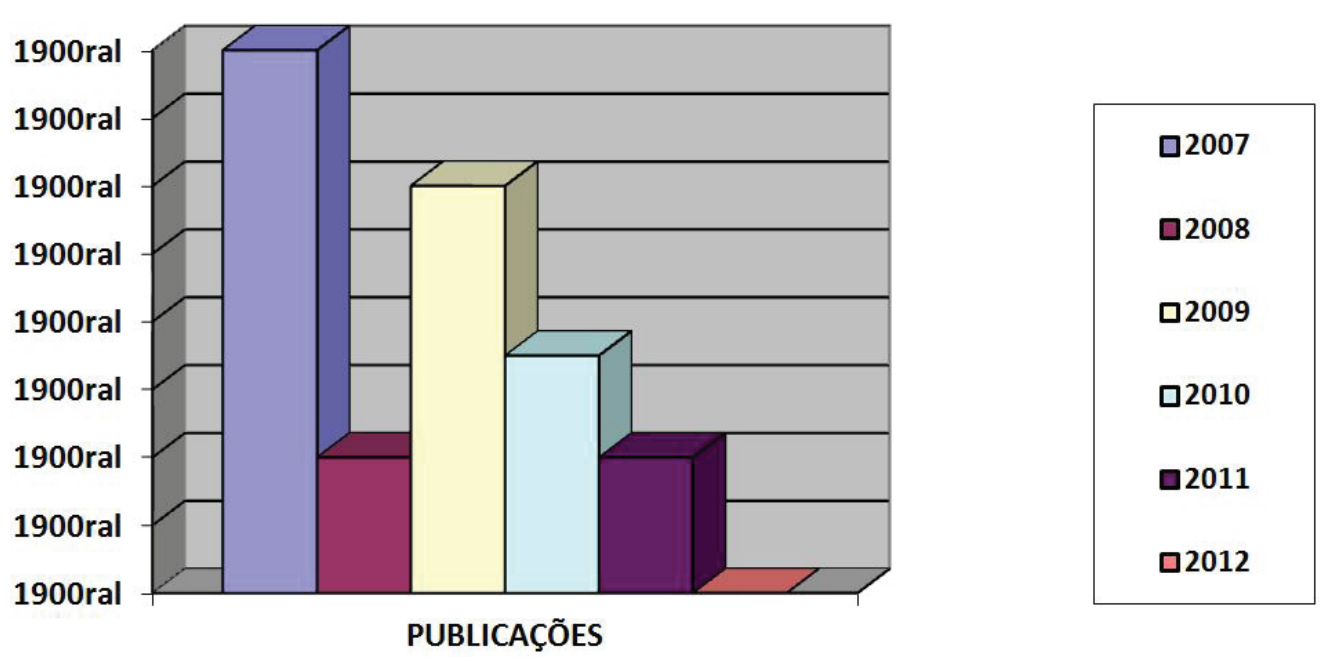

Figura 5.1 - Gráfico da produção científica sobre DSS publicada na Biblioteca Virtual de Saúde, 2007-2012.

Fonte: informações reunidas pelo autor da pesquisa mediante busca na Biblioteca Virtual de Saúde.

De acordo com os dados referentes ao ano de publicação das produções sobre os DSS, obtivemos 16 publicações do ano de 2007, 4 publicações do ano de 2008, 12 publicações do ano de 2009, 7 publicações do ano de 2010, 4 publicações do ano de 2011. Não houve qualquer publicação que atendesse aos critérios de seleção no ano de 2012. As revistas e periódicos que apresentaram maior produção de DSS nestes anos foram: CEBES (34\%), Cadernos de Saúde Pública (14\%) e Ciência e Saúde Coletiva (11\%). Em relação ao tipo de produção, uma correspondeu ao tipo quali-quantitativa $(2,3 \%)$ e as demais são qualitativas $(97,7 \%)$. 
Nossa análise permitiu identificar algumas linhas categóricas abordadas nos 43 artigos. A discussão apresentada a seguir guia-se pelos eixos: 1) a concepção de determinantes sociais da saúde; 2) pobreza e iniquidades de saúde.

\subsection{O QUE SÃO DETERMINANTES SOCIAIS DE SAÚDE?}

De certo, uma das tarefas dos pesquisadores em torno de um objeto de estudo em comum é a de defini-lo, apontar o seu significado mais substancial e o contexto que o requisita. No caso da produção científica brasileira sobre os determinantes socais da saúde, a mais bem desenvolvida consta em artigo de Paulo Marchiori Buss e Alberto Pelligrini Filho (2007), não só por apresentar uma concepção bem definida, mas também por apresentar um debate por meio do qual se chegou a ela. Referido artigo será a base da discussão desta seção, junto a outras contribuições. ${ }^{4}$

Para Buss e Pellegrini Filho (2007), o conflito entre os enfoques biológicos e sociais a respeito do processo saúde-doença está no centro do debate entre vários estudiosos em todo o mundo. Levando em consideração que o paradigma biologicista da saúde imbricado no modelo biomédico está presente desde os primórdios da sociedade, os referidos autores destacam sua forte influência nas práticas de saúde até os dias de hoje. Contudo, a tensão entre diferentes explicações (mais ou menos centradas no biológico) vem desde o século XVIII.

Martins (2010) afirma que no final do século XVIII, já existia a convicção de serem, saúde e doenças, fenômenos de muita importância para o indivíduo, para a comunidade e para o Estado. A percepção sobre as causalidades das doenças passou a se concentrar nos fatores externos. Vale destacar que entre os diversos paradigmas explicativos do fenômeno do contágio e da disseminação de doenças consta o predomínio da teoria dos miasmas por um bom tempo. Em meados do século XIX, a teoria miasmática tentava explicar os problemas de saúde, decorrentes dos novos processos de industrialização e urbanização, afirmando que a doença era causada por miasmas provindos de dejetos emanados do solo (BUSS; PELLEGRINI FILHO, 2007).

Ao final do século XIX, o trabalho dos bacteriologistas Koch e Pasteur resultou em novo paradigma, que direcionava o estudo do processo saúde-doença para o âmbito laboratorial, baseando-se em ramos da microbiologia e na intervenção

4 O Relatório Final da Comissão Nacional sobre Determinantes Sociais da Saúde (CNDSS), intitulado As Causas Sociais das Iniquidades em Saúde no Brasil (2008) também apresenta uma concepção bem definida. O documento analisa o impacto dos DSS em seus diversos níveis de atuação, com especial ênfase nas iniquidades em saúde. Contudo o artigo de Buss (2007) demonstra um direcionamento mais objetivo, além de ter caráter mais acadêmico, enquanto aquele relatório tem caráter mais técnico. 
sobre doenças específicas, devido às epidemias da época, como a de varíola, por exemplo (BUSS; PELLEGRINI FILHO, 2007).

Com o advento da medicina social, ${ }^{5}$ no século XX, estabelece-se um conflito entre o enfoque social e o biológico no processo saúde-doença, mas ainda prevalece o conceito de saúde pública orientado para o controle de doenças específicas. Desse modo, as ações da saúde pública se distanciam das questões políticas e das reformas sociais e sanitárias (BUSS; PELLEGRINI FILHO, 2007).

A criação da Organização Mundial da Saúde (OMS) em 1948 foi importante para a formulação de uma nova concepção de saúde, que leva em consideração sua dimensão social, sem negar a dimensão biológica. A definição de saúde como um estado de completo bem-estar físico, mental e social, e não meramente a ausência de doença ou enfermidade, inserida na Constituição da OMS. Para Buss e Pellegrini Filho (2007) é uma clara expressão de concepção bastante ampla da saúde, para além de um enfoque centrado na doença.

Entretanto, entendemos que esta definição apresenta algumas limitações. Souza (2012), baseado em Rezende (1989), afirma que equiparar saúde ao bem-estar é pura tautologia, uma redundância que nada diz. Ademais,

o adjetivo "completo" expressa uma condição de estado absoluto, na qual ou se tem saúde ou não se tem, não existindo um processo, busca ou conflito. Nesta concepção, o suposto bem-estar se configura como um equilíbrio entre o físico, mental e social, e a doença seria o desequilíbrio, persistindo uma dicotomia entre saúde e doença (tanto quanto a concepção anterior, que a OMS tentou combater). A definição da OMS não leva em consideração que os homens, ao se depararem com situações que ameaçam a sua saúde, podem instituir um conflito, um embate, na busca por transformar o que lhes é hostil. Neste enfrentamento, eles não estão nem "sãos" (em equilíbrio) nem “doentes" (em desequilíbrio); estão lutando. Ao desconsiderar este conflito, cancela-se a dinamicidade do processo saúde-doença, conferindo-lhe caráter estático (SOUZA, 2012, p. 153).

Apesar disso, sem dúvida, a definição da OMS abre a possibilidade, ao menos, de questionamento do modelo biomédico de saúde. Desta possibilidade é que observamos o surgimento da discussão sobre os determinantes sociais da saúde (DSS), especialmente a partir da década de 1990. Assim, os DSS são entendidos como as condições sociais em que os indivíduos vivem e trabalham (BUSS; PELLEGRINI FILHO, 2007).

5 "Com o aparecimento da Medicina Social entre os séculos XVIII e XIX é que surgem as primeiras investigações sistemáticas sobre as relações entre saúde e condições de vida de grupos e classes sociais, como também um conjunto articulado de proposições para a intervenção. A Medicina Social tem se preocupado em entender como a dinâmica do processo saúde/doença, a relação entre a estrutura da atenção e da sociedade, contribuem para a obtenção de níveis cada vez melhores de saúde e bem-estar” (FOUCAULT, 2003 apud MARTINS, 2010, p. 28). 
No caso brasileiro, vemos que em 13 de março de 2006, por meio de Decreto Presidencial, foi criada a Comissão Nacional sobre Determinantes Sociais da Saúde (CNDSS) no país. Para tanto, a CNDSS define os Determinantes Sociais da Saúde (DSS) como os fatores sociais, econômicos, culturais, étnicos/raciais, psicológicos e comportamentais que influenciam a ocorrência de problemas de saúde e seus fatores de risco na população (BUSS; PELLEGRINI FILHO, 2007).

Essa discussão avançou consideravelmente na passagem do século XX para o XXI, surgindo diversos modelos explicativos. Buss e Pellegrini Filho (2007) destacam dois deles: o modelo Dahlgren e Whitehead e o modelo de Diderichsen e Hallqvist. A seguir, um resumo de ambos.

O modelo de Dahlgren e Whitehead explica os DSS organizados em camadas. Cada camada possui um grau diferente de determinação sobre o processo saúde-doença, sendo maior a determinação quanto mais externa for a camada. Assim, a camada mais interna possui o menor grau de determinação; a mais externa, o maior. De acordo com este modelo, os fatores individuais (idade, sexo, fatores genéticos etc.) estão situados na camada mais interna. $\mathrm{Na}$ camada seguinte, observa-se o estilo de vida dos indivíduos, seguida por uma camada para representar a coesão social (redes sociais e comunitárias). Na penúltima camada temos os fatores relacionados às condições de vida e de trabalho; e, na última, aquela de maior determinação, encontramos as condições socioeconômicas, culturais e ambientais (BUSS; PELLEGRINI FILHO, 2007).

Já o modelo de Diderichsen e Hallqvist retrata a estratificação social gerada pelo contexto social e os diferenciais de saúde resultantes deste mecanismo. Afirma-se, em linhas gerais, que a exposição a riscos, a vulnerabilidade à doença e o diferencial de consequências sociais ou físicas são determinadas pela posição social do indivíduo (BUSS; PELLEGRINI FILHO, 2007).

Em suma, a discussão sobre os DSS permite compreender que os diversos problemas sociais (pobreza, miséria, violência, crise ambiental etc.) e o contexto político-econômico interferem nos níveis de saúde da coletividade humana. No caso da produção científica brasileira sobre a temática, dentre os aspectos que citamos, constatamos que há ênfase para a relação pobreza e iniquidades de saúde e para a caracterização do contexto político-econômico atual (globalizado) dos DSS, além de, a partir daí, surgirem propostas de intervenção.

\subsection{POBREZA E INIQUIDADES DE SAÚDE}

Como afirma Carvalho e Buss (2009), estudos que relacionam a saúde das populações e as desigualdades nas condições de vida constatam que, uma vez superado um determinado limite de crescimento econômico de um país, um crescimento adicional da riqueza não se traduz, necessariamente, em melhorias sig- 
nificativas das condições de saúde. A partir desse nível, o fator mais importante para explicar a situação geral de saúde de um país não é sua riqueza total, mas a maneira como ela se distribui. Para Magalhães (2007) entender os diferentes perfis de doença e suas mediações sociais ultrapassa, portanto, o estudo de variações biológicas e incorpora o foco na dimensão social das vulnerabilidades e nos mecanismos complexos que sustentam a relação entre a dinâmica das desigualdades e as condições de saúde.

Magalhães (2007) também reconhece que a pobreza e a desigualdade social possuem múltiplas faces e dimensões, portanto, estas não se articulam apenas em uma "causalidade bidirecional". Por seu turno, a pobreza consiste em um conceito multidimensional e por assim dizer, uma situação real de vida. Diante disso, a autora esclarece que, embora haja uma articulação entre renda per capita e condições de saúde, alguns estudos mostram que à medida que se avança nas classes de renda, o efeito desta variável tende a diminuir. Ou seja, o aumento da renda parece ter mais impacto na saúde dos mais pobres.

Diante da problemática da pobreza, Fleury-Teixeira (2009) aponta a exposição a agentes biológicos, químicos ou físicos danosos, a deficiência nutricional, o desgaste físico generalizado ou o esforço repetitivo no trabalho como características das condições sociais de pobreza ou miséria que ainda acometem a maior parte da população mundial. Por seu turno, a pobreza não representa apenas a falta de acesso a bens materiais ou a falta de voz ante as instituições do Estado e da sociedade como citam Carvalho e Buss (2009). A pobreza remete o indivíduo a um quadro de vulnerabilidade social que compromete a capacidade de atuar a favor de sua saúde e da coletividade.

Reforçando com esta temática, Rigotto e Augusto (2007) levantam a discussão a respeito de mais alguns aspectos relacionados à pobreza, demonstrando que a insuficiência de serviços básicos de saneamento, de coleta e destinação do lixo e condições precárias de moradia, tradicionalmente relacionadas à pobreza e ao subdesenvolvimento, incluindo-se a poluição ambiental, atuam diretamente nas condições de saúde da população.

De fato, os indicadores apontam que a diferença na esperança de vida ao nascer alcança 27 anos entre os países mais ricos e mais pobres; a mortalidade infantil é de 100 por mil nascidos vivos nos menos desenvolvidos e de apenas 6 por mil nos países de alta renda; e a diferença na mortalidade de menores de 5 anos é ainda maior: 159 por mil nascidos vivos nos países menos desenvolvidos e 6 por mil nos de renda alta (BUSS, 2007).

Entendemos que não podemos ignorar os dados, uma vez que eles nos indicam a complexidade da problemática. Nesta lógica de produção é que surgem as iniquidades em saúde. Whitehead as define como as desigualdades sociais que podem ser evitáveis e que além de sistemáticas e relevantes são também injustas 
e desnecessárias (WHITEHEAD, 2000). Diante das disparidades, alguns autores citam fenômenos que ocorrem em âmbito mundial. Meneghel et al. (2009), por exemplo, aponta que a exploração sexual de crianças e adolescentes se dá por meio da prostituição, do turismo sexual, da pornografia e do tráfico para fins sexuais. Já Costa e Tambellini (2009) pontuam que os empregos precários já não resultam da ausência de crescimento econômico, uma vez que se tornaram inerentes ao próprio modelo de crescimento. Isto equivale a dizer que desenvolvimento econômico não mais significa desenvolvimento social.

Convém ressaltar que o processo de precarização do trabalho é resultado do novo sociometabolismo do capital. A principal forma histórica de precariedade social é o sistema do trabalho assalariado que predomina nas sociedades burguesas há séculos. No processo de produção, os trabalhadores são excluídos do aproveitamento do que eles mesmos construíram. Neste contexto é que Alves (2007) diferencia os conceitos de precariedade e precarização do mundo do trabalho, afirmando que a precariedade constitui uma condição socioestrutural que caracteriza o trabalho vivo e a força de trabalho enquanto mercadoria. Por outro lado, a precarização

diz respeito a um modo de reposição sócio-histórica da precariedade. Se a precariedade é uma condição, a precarização é um processo que possui irremediável dimensão histórica determinada pela luta de classes e pela correlação de forças políticas entre capital e trabalho (grifo do autor) (ALVES, 2007, p. 114).

Diante das contribuições destes autores, parece ser inegável o entrelaçamento entre a pobreza e os demais problemas sociais, indicando a existência de uma questão una, apesar de se expressar de diferentes formas. Contudo, neste quesito, constatamos que falta, aos autores aqui revisados, uma aproximação com o debate sobre a questão social, em suas raízes materiais e humanas, o que acreditamos possibilitar uma argumentação mais próxima da real dinâmica das relações sociais capitalistas.

\subsection{REPENSANDO OS DSS A PARTIR DE UMA PERSPECTIVA CRÍTICA}

A concepção de DSS que vem sendo apresentada não desvela a base nem a dinâmica social que estão na raiz da problemática da saúde, uma vez que retrata cada problema social como se fosse um fragmento da realidade. De fato, podemos perceber que alguns autores (podemos citar: BUSS; PELLEGRINI FILHO, 2010; BUSS, 2007; MARTINS, 2010) até consideram o problema em questão e do ponto de vista mais imediato atribuem a causa às desigualdades sociais e econômicas, mas eles param por aí. Não constroem o caminho de volta à raiz do problema, de 
modo que o conhecimento produzido se torna insuficiente, incapaz de relacionar verdadeiramente as condições de vida das pessoas e seu estado de saúde, não reconhecendo o fio condutor que há entre eles.

Em uma perspectiva contrária à apresentada por tais autores, podemos mencionar Pimentel (2007). Ele aborda a "questão social" 6 como um fenômeno que adquire conotação política no momento em que a classe trabalhadora percebe o quanto a pobreza crescia à medida que a sociedade se tornava capaz de produzir mais bens e serviços, passando a reagir às condições de vida geradas pelo pauperismo, organizando-se como classe em torno de interesses comuns. Neste sentido, reconhecemos a questão social em suas dimensões humana, social e material. Sua raiz humana e social, em seu caráter político, decorre do momento em que a classe trabalhadora toma consciência de sua exploração e luta contra isso. A raiz material da questão social é a lei geral de acumulação do capital, a qual origina toda a questão social.

Em seu resgate à lei geral de acumulação capitalista, Pimentel (2007) indica a existência de dois momentos diferentes, explicando que inicialmente há composição constante do capital, resultando em acúmulo de capital variável (força de trabalho - único elemento do trabalho capaz de gerar valor) e aumento de salários, mas até certo limite, de modo a não se tornar uma ameaça para o próprio sistema. Passado esse momento, o capital passa a exigir produtividade crescente. Portanto, a massa de capital constante (meios de produção) aumenta em relação ao capital variável. Acumular capital variável e, consequentemente, mais-valia é um requisito imprescindível para esse modo de produção. Acrescenta-se, a isto, a formação de um exército industrial de reserva (EIR), isto é, uma massa de desempregados que ultrapassa as necessidades médias da expansão do capital, em decorrência do aumento do capital constante em relação ao variável enquanto requisito da produtividade crescente. Desse modo,

o pauperismo se constitui na camada social que perdeu a capacidade de vender sua força de trabalho e tem que mendigar a caridade pública. Ele se expressa na forma como o capital se apropria da força de trabalho da classe trabalhadora, com a finalidade de assegurar a sua reprodução e a acumulação da riqueza por parte dos capitalistas e, contraditoriamente, produz a acumulação da miséria da classe que gerou seu produto como capital (PIMENTEL, 2007, p. 52).

Os autores revisados ignoram a origem do pauperismo, bem como anulam o fio condutor que há entre eles, considerando os problemas como se estivessem, de

6 A expressão "questão social” foi utilizada inicialmente por volta da década de 1930 do século XIX como resultado dos impactos gerados pela onda industrializante iniciada no século XVIII. A expressão surge para denominar o fenômeno que tomava forma em larga escala na Europa ocidental: o pauperismo, bem como seus desdobramentos (NETTO, 2001). 
fato, isolados. Carvalho e Buss (2009) explicam a situação geral de saúde de uma população por meio da distribuição de sua riqueza material. Magalhães (2007) se limita a reconhecer que o desemprego traz profundas repercussões nas condições de saúde, mas não aponta o caráter estrutural do desemprego e sua dinâmica a partir da lógica de acumulação. Ademais, Fleury-Teixeira (2009) e Carvalho e Buss (2009) atribuem a causa da pobreza à má distribuição de renda. Significaria dizer que caso houvesse uma melhor distribuição, a pobreza seria extinta. Isto não é verdade. Nesta lógica de produção, o pauperismo, assim como a criação do EIR são necessidades para o acúmulo e a expansão do capital.

Meneghel et al. (2009) trazem mais algumas considerações ao examinar a desigualdade social decorrente da organização socioeconômica produtora de iniquidades e exclusões como o determinante fundamental da exploração sexual de crianças e adolescentes na sociedade atual. Tambellini e Costa (2009) também reconhecem as condições de vida, acrescentando que estas são "determinadas” pelo "lugar que cada um ocupa na hierarquia social”. Entendemos que não podemos ignorar a dimensão apontada por estes autores, uma vez que eles nos indicam a complexidade da problemática. No entanto, além disto, é necessário perceber que os fatores que prejudicam a saúde são gerados pelo antagonismo capital-trabalho, devido à exploração da força de trabalho vivo para gerar capital, condição decorrente da lei geral de acumulação capitalista.

Em razão disso, a noção de iniquidades compreende uma condição estrutural de antagonismo entre capital e trabalho, uma vez que a dinâmica do capital produz, ao mesmo tempo, acúmulo de riqueza por um lado e pobreza do outro. Significa ainda que enquanto houver acúmulo do capital, isto é, a expropriação pelos capitalistas do que é produzido pela classe trabalhadora, haverá as expressões da questão social, compreendidos pelos autores como determinantes sociais de saúde, em uma visão fragmentada que cancela a origem única de cada suposto determinante.

Neste contexto, os modelos em torno dos DSS determinam intervenções apenas pontuais a fim de minimizar os problemas no âmbito social dos indivíduos e grupos. Não poderia se esperar mais do que isso, uma vez que os modelos não compreendem detalhes acerca das relações e mediações entre os níveis e a gênese das iniquidades.

Em meio a isto, ficam bem claros os limites das políticas sociais. Nos moldes do "Estado social", as políticas sociais são sufocadas pelo neoliberalismo, isto é, atuam no sentido de reproduzir o capital. Alguns direitos são concedidos parcialmente à classe trabalhadora na intenção de controlar as reivindicações pelos direitos. Citamos como exemplo as políticas relacionadas ao mercado de trabalho, educação e seguridade social. Há, sob esse ponto de vista, a necessidade de um sistemático acompanhamento de políticas econômicas e sociais para avaliar seu 
impacto e diminuir seus efeitos sobre a estratificação social, com manutenção da mesma estrutura societária, quando não reproduzindo-a (LESSA, 2011).

Acreditamos que intervir nas sequelas da questão social, apesar de ter alguma importância, constitui uma tarefa que deixa intactas suas raízes mais profundas. Isto se reproduz no enfrentamento específico da problemática da saúde, que se encontra plasmada na questão social. Resgatemos o pensamento de Laurell (1982) ao se apropriar do materialismo histórico e dialético, quando afirma que o processo saúde-doença é determinado pelo modo como o homem se apropria da natureza em um dado momento, isto é, a apropriação que se realiza por meio de processo de trabalho baseado em determinado desenvolvimento das forças produtivas e relações sociais de produção. Os mesmos processos que determinaram a estrutura da sociedade são os que geram as desigualdades sociais.

Acreditamos nas políticas sociais como proposta de intervenção desde que estejam articuladas a uma proposta revolucionária que se deve dar com a conscientização da classe trabalhadora. Para nós as estratégias de intervenção devem estar associadas à luta prioritária, ou seja, em conformidade com a classe trabalhadora, principal interessada em que haja mudança.

Por fim, em uma perspectiva da totalidade, preferimos compreender que existe, sim, uma determinação social da saúde, mas que não se segmenta em diversos determinantes. Ao invés disto, a problemática da saúde encontra suas raízes na sociedade capitalista, em uma relação direta com a "lei geral da acumulação capitalista", como a mola mestra que produz a pauperização de uma grande massa de homens. Em meio a este processo de pauperização, a degradação/aviltamento da saúde comparece, dialeticamente, enquanto expressão e requisito.

\subsection{CONSIDERAC̣ÕES FINAIS}

As atuais produções limitam-se apenas a descrever os DSS. Algumas, ainda que de forma limitada, propõem estratégias de intervenção, embora sequer apontem em que sociedade elas têm sido produzidas. Desse modo, percebemos que a temática vem sendo discutida a partir de uma fragmentação da realidade social em fatores que parecem ser autônomos e sem uma determinação comum, isto é, ocultam a raiz da problemática e desconsideram a natureza e a dinâmica da sociedade capitalista.

Para tal, os recentes estudos se aproximam das formulações de clássicos como Asa Cristina Laurell ou Cecília Donnangelo quando reconhecem que existe uma determinação social, mas depois se afastam ao ponto de se tornarem contrapostos, centrando a discussão nos fatores isolados e ignorando a totalidade que os produziu. Por assim dizer, estes autores revelaram-se convencidos de que as atividades da CNDSS e seus desdobramentos futuros seriam uma valiosa contribuição 
para o avanço do processo de reforma sanitária brasileira e para a construção de uma sociedade mais humana e justa. Nós estamos convencidos de que a construção de uma sociedade mais humana e justa só seria possível com a superação do capital e, portanto, do trabalho baseado na exploração do homem pelo homem, uma vez que nesta forma de trabalho se consubstancia, inclusive, o momento predominante da determinação social do processo saúde-doença.

\section{REFERÊNCIAS}

ALVES, Giovanni. Dimensões da reestruturação produtiva. 2. ed. Londrina: Praxis; Bauru: Canal 6, 2007.

ANDERSON, Perry. Balanço do neoliberalismo. In: SARDER, Emir; GENTILI, Pablo. Pós-neoliberalismo: as políticas sociais e o Estado. Rio de Janeiro: Paz e Terra, 1995. BUSS, Paulo Marchiori. Globalização, pobreza e saúde. Ciência \& Saúde Coletiva, Rio de Janeiro, v. 12, n. 6, p. 1575-1589, nov./dez. 2007.

BUSS, Paulo Marchiori; FILHO, Alberto Pellegrini. A Saúde e seus determinantes sociais. Physis: Revista Saúde Coletiva, Rio de Janeiro, vol. 17, n.1, p.77-93, 2007. CARVALHO, Antonio Ivo; BUSS, Paulo Marchiori. Determinantes sociais na saúde, na doença e na intervenção. In: GIOVANELLA, Lígia et al. (Org.). Políticas e Sistemas de Saúde no Brasil. Rio de Janeiro: Fiocruz, 2009. p. 141-166.

FLEURY-TEIXEIRA, Paulo. Uma Introdução Conceitual à Determinação Social da Saúde. Saúde em Debate, Rio de Janeiro, v. 33, n. 83, p. 380-387, set./dez. 2009.

GIFFIN, Karen Mary. Financeirização do estado, erosão da democracia e empobrecimento da cidadania: tendências globais? Ciência \& Saúde Coletiva, Rio de Janeiro, v. 12, n. 6, p. 1491-1504, nov./dez. 2007.

LAURELL, Asa Cristina. La salud-enfermedad como proceso social. Revista latinoamericana de salud, México, v. 1, n. 2, p. 7-25, 1982.

LAVINA, Lena. Gasto social no Brasil: programas de transferência de renda versus investimento social, Ciência \& Saúde Coletiva, Rio de Janeiro, v. 12, n. 6, p. 1463 1476, nov./dez. 2007.

LESSA, Sergio. Capital e Estado de Bem-Estar: o caráter de classe das políticas públicas. Maceió: Instituto Luckács, 2011. Mimeografado. No prelo.

MAGALHÃES, Rosana. Monitoramento das desigualdades sociais em saúde: significados e potencialidades das fontes de informação. Ciência \& Saúde Coletiva, Rio de Janeiro, v. 12, n. 3, p. 667-673, maio/jun. 2007.

MARTINS, Ana Maria Barbieri Bedran. Análise da Produção Científica sobre os Determinantes Sociais de Saúde na Faculdade de Saúde Pública - USP. 2010. 117 p. Dissertação (Mestrado em Saúde Pública) - Faculdade de Saúde Pública, Universidade de São Paulo, São Paulo, 2010. 
NETTO, João Paulo. Cinco notas a propósito da questão social. Temporalis: revista da ABEPSS, Brasília, DF, v. 2, n. 3, p. 45-49, 2001. Introdução ao estudo do método de Marx. São Paulo: Expressão popular, 2011. NUNES, Everardo Duarte. Cecília Donnangelo: pioneira na construção teórica de um pensamento social em saúde. Ciência \& Saúde Coletiva, Rio de Janeiro, v. 13, n.3, p. 909-916, maio/jun. 2008.

PIMENTEL, Edlene; COSTA, Gilmaísa Macedo. Questão social e desigualdade: novas formas, velhas raízes. Revista Ágora: políticas públicas e serviço social, Rio de Janeiro, v. 2, n. 4, p. 1-26, jul. 2006.

REZENDE, Ana Lúcia Magela de. Saúde: dialética do pensar e do fazer. 2. ed. São Paulo: Cortez, 1989.

SOUZA, Diego de Oliveira. A problemática do conhecimento. 2011. Arapiraca. Aulas de metodologia científica no curso de graduação em Enfermagem da Universidade Federal de Alagoas, campi Arapiraca. Mimeografado.

TEIXEIRA, Francisco José Soares. O neoliberalismo em debate. In: TEIXEIRA, Francisco José Soares et al. Neoliberalismo e reestruturação produtiva: as novas determinações do mundo do trabalho. 2. ed. São Paulo: Cortez, 1998. WHITEHEAD, Margaret. The concepts and principles of equity and health. Copenhagen: World Health Organization Regional Office for Europe, 2000. 